\title{
PML, SUMOylation, and senescence
}

\author{
Lisa Ivanschitz ${ }^{1,2,3}$, Hugues De The $e^{1,2,3,4,5 *}$ and Morgane Le Bras ${ }^{1,2,3}$ \\ 1 University Paris Diderot, Sorbonne Paris Cité, Hôpital St. Louis, Paris, France \\ 2 INSERM UMR 944, Equipe labellisée par la Ligue Nationale contre le Cancer, Institut Universitaire d'Hématologie, Hôpital St. Louis, Paris, France \\ ${ }^{3}$ CNRS UMR 7212, Hôpital St. Louis, Paris, France \\ ${ }^{4}$ Pole Sino-Francais des Sciences du Vivant et de Génomique de I'Hôpital Rui-Jin, Rui-Jin Hospital affiliated with Jiao Tong University, Shanghai, China \\ ${ }^{5}$ Service de Biochimie, AP-HP, Hôpital St. Louis, Paris, France
}

Edited by:

Paolo Pinton, University of Ferrara,

Italy

Reviewed by:

Robert Friis, University of Berne,

Switzerland

Keisuke Ito, Albert Einstein College of

Medicine, USA

*Correspondence:

Hugues De Thé, Hôpital St. Louis, 1

Avenue Claude Vellefaux, 75454 Paris

10, France

e-mail: dethe@univ-paris-diderot.fr
Since its discovery, 25 years ago, promyelocytic leukemia (PML) has been an enigma. Implicated in the oncogenic PML/RARA fusion, forming elusive intranuclear domains, triggering cell death or senescence, controlled by and perhaps controlling SUMOylation... there are multiple PML-related issues. Here we review the reciprocal interactions between PML, senescence, and SUMOylation, notably in the context of cellular transformation.

Keywords: PML, senescence, SUMO, tumor suppression, p53

\section{INTRODUCTION}

Senescence is a permanent cell cycle arrest discovered in human fibroblasts in culture, a process that limits their replicative potential (1). Today, senescence is considered as an important anticancer mechanism, probably the first physiological defense against cellular transformation. Moreover, senescent cells that have lost the ability to divide are the underlying mechanism of aging $(2,3)$. Different types of signals can initiate senescence. Replicative senescence is principally caused by telomere shortening upon repeated cells divisions (4). Beyond a certain point of telomere erosion, the DNA damage response is activated and mediated through the p53 pathway, similarly to double strand breaks. As telomeres cannot be repaired, senescent cells are characterized by persistent reparation foci $(5,6)$. Premature senescence can also be provoked by signals such as oncogene activation, tumor-suppressor loss, or sustained stress conditions. Retinoblastoma protein (pRB) and p53 suppressor pathways are both major downstream effectors of this stress-induced senescence (7-9).

SUMOylation is a post-translational modification consisting of covalent binding of Small Ubiquitin related Modifier (SUMO) onto a target protein. SUMOs belong to the Ubiquitin-like protein (Ubl) family, and have a very similar three-dimensional structure compared to ubiquitin, while sharing only $20 \%$ of sequence identity. In mammals, four SUMO paralogs have been identified. SUMO- 1 shares $50 \%$ sequence identity with SUMO-2/3, and $86 \%$ with SUMO-4. SUMO-2 and 3 are usually pooled together as SUMO-2/3 as they are $95 \%$ identical to each other and cannot be separately identified. While SUMO- 1 and SUMO-2/3 are ubiquitously expressed, SUMO-4 expression was only found in the liver and consequently its function will not be discussed here (10). SUMOylation is a dynamic process consisting of rapid conjugation and de-conjugation cycles. Target proteins are usually very transiently modified and their SUMOylated forms often constitute only a very small fraction of the total protein pool. SUMO conjugation is performed by specific enzymes in three steps: the SUMO peptides are maturated by SUMO-specific proteases (SENP family), activated by the E1 SUMO activating complex, then transferred onto the E2 SUMO ligase Ubc9 which then conjugates SUMO onto lysine residues of target proteins (11). Substrate interaction and modification can directly be performed by Ubc 9 and usually depends on the presence of the short SUMOylation consensus motif $(\Psi \mathrm{KxD} / \mathrm{E})(12,13)$. E3 SUMO ligases, which link Ubc9 to the substrate proteins, can also improve target recognition, notably in the absence of SUMOylation consensus sites. The first E3 ligases described were the family of proteins Protein Inhibitor of Activated STAT (PIAS) (14). SUMOs may be removed from their targets by SENP enzymes, the same family of proteases that performs SUMO maturation (15). SUMO conjugation can alter protein-protein interactions, change protein intracellular localization, or directly modify activities resulting in changes in transcription, replication, chromosome segregation, and DNA repair. Importantly, SUMO conjugation has been repeatedly associated to stress response (16).

The promyelocytic leukemia (PML) tumor-suppressor is the key organizer of PML Nuclear Bodies (NBs) $(17,18)$. These PMLdriven structures are characterized by the accumulation of a very large number of nuclear partner proteins. NBs are implicated in multiple cellular processes including virus defense, apoptosis, and senescence. PML NBs are strongly associated with SUMOylation process (19). SUMO was initially described as a PML binding protein (20), SUMO paralogs accumulate in NBs and even NBbiogenesis was proposed to rely on PML SUMOylation $(21,22)$. PML directly interacts with Ubc9 (23) and may be SUMOylated on three lysine residues. SUMOylation of K160 is essential for PML ability to recruit nuclear partners into NBs (24). SUMOylation state or presence of a SUMO Interacting Motif (SIM) in protein partners were proposed to be the major signals driving their recruitment into NBs $(25,26)$. Moreover, other key players 
in the SUMO-conjugation pathway were proposed to accumulate in NBs: several SENP and SUMO E3 ligases, as well as the SUMO-dependent ubiquitin ligase RNF4 (27). Overall, PML NBs are intimately associated with the SUMO pathway, although many functional aspects remain unclear.

Both PML and SUMO overexpression induces senescence. Here, we will discuss the potential links between these two mechanisms.

\section{PML INDUCES SENESCENCE}

Promyelocytic leukemia NBs have been implicated in various cellular processes. Importantly, PML expression and localization are profoundly changed during oncogenic transformation. First evidence came from the PML/RARA oncoprotein responsible of acute promyelocytic leukemia (APL). PML/RARA oncogene activity relies on its transcriptional repressive activity, but also on its dominant negative action on PML NBs biogenesis $(18,28)$. Notably, the two active drugs in APL, retinoic acid and arsenic, both allow the reformation of PML NBs, as the result of PML/RARA degradation $(29,30)$. Moreover, partial or complete loss of PML expression was observed in multiple cancers (31). Several studies have investigated the underlying mechanisms for NBs-loss during tumor progression and have implicated PML degradation, more than loss of PML gene expression $(32,33)$. It was proposed that PML NBs could prevent malignant transformation by promoting senescence (34). Then, loss of PML NBs during tumor progression could reflect loss of this senescence failsafe.

Promyelocytic leukemia plays a key role in senescence induction as demonstrated after stress, DNA damage, oncogene activation, or simply during replicative senescence. Initially, two key observations have directly implicated PML in senescence: Ras-induced senescence is lost in a $\mathrm{pml}^{-/-}$context, while conversely, PML overexpression induces premature senescence (35-37). Moreover, PML protein level is increased in replicative or Ras-induced senescent cells. Thus, PML expression is critical for the control of cellular senescence and can be achieved both at transcriptional and post-transcriptional levels. PML promoter contains interferon (IFN) and p53 response elements and can thus be induced by IFN signaling or p53 activation $(38,39)$. PML up-regulation can be critical in senescence induction, since IFN $\beta$ treatment can induce cellular senescence in a PML/p53 dependent manner $(40,41)$. Genotoxic drug induced senescence was also shown to increase PML transcription through JAK1/STAT1 pathway and IFN production $(42,43)$. Indeed, senescent cells are characterized and entertained by secretion of multiple cytokines, IFN, and pro-inflammatory factors. This condition has been called senescence-associated secretory phenotype (SASP) (44).

At the protein level, multiple PML degradation pathways were described, several enforced by oncogenic proteins. As an example, proteins such as E6AP ubiquitin ligase, E2F transcription regulator E2FBP1, or Pin1 isomerase promote PML degradation or disrupt NBs formation. Loss or down-regulation of these proteins causes PML stabilization and tumor suppression by senescence induction in human primary fibroblasts or in cancer cells (45-47). Casein Kinase 2 (CK2) and PIAS1 SUMO ligase also regulate PML stability and senescence induction. PIAS1-dependent SUMOylation of PML increases CK2-PML interaction leading to PML phosphorylation at serine 517, ubiquitination, and degradation. Down-regulation of PIAS1 or mutation of serine 517 stabilizes PML and provokes cell cycle arrest $(33,48)$. Finally, in response to Ras activation, PML is up-regulated through a selective translation initiation depending on PML mRNA 5'UTR and involving the MEK/ERK/mTOR pathway (49). All of these examples demonstrate that PML levels are important in the fine-tuning of senescence induction.

\section{A SINGLE ISOFORM CONFERS PML-INDUCED SENESCENCE}

Promyelocytic leukemia is expressed as a number of $3^{\prime}$ splice variants that encode C-terminal distinct isoforms named PML I to PML VII. Only PML IV isoform overexpression induces senescence in primary cells (37). The mechanism by which PML IV isoform elicits this irreversible growth arrest remains controversial and is believed to involve both p53/p21 and p16/Rb pathways. PML IV overexpression stabilizes and activates $\mathrm{p} 53$ by inducing its phosphorylation and acetylation (35-37, 50). Since all PML isoforms are able to recruit p53 into NBs, PML IV ability to stabilize p53 is not due to a specific recruitment of p53, but rather of critical partners implicated in p53 modification. During Ras-induced senescence, $\mathrm{CBP}$ is recruited to NBs to acetylate p53 (36). Yet, CBP is recruited into NBs by all isoforms and not only PML IV, making it unlikely that CBP is the key limiting factor that allows p53 activation upon PML IV overexpression (37). MORC3 (microrchidia3)-ATPase and the TGF- $\beta$ negative regulator SnoN both favor senescence, p53 stabilization, and are located in NBs. Moreover, SnoN induced senescence and p53 stabilization are abrogated upon PML extinction $(51,52)$. Following cellular stress, MOZ acetyltransferase is similarly recruited to NBs, acetylates p53, and enhances p 21 expression leading to premature senescence (53). It has also been proposed that specific targeting of HIPK2 into NBs by PML IV would phosphorylate p53, thus facilitating CBP action (54-56). On the contrary, SIRT1 deacetylase is recruited in NBs upon PML IV or Ras expression, to bind and deacetylate p53. Accordingly, overexpression of SIRT1 in MEF cells antagonizes PML IV induced senescence (57). This is also the case for MageA2 overexpression, which interferes with p53 acetylation at NBs and with PML IV-dependent activation of p53 (58). These studies point out the surprising number of $\mathrm{p} 53$ regulators recruited to NBs and question the respective importance of each one. The use of HPV oncoprotein E6 and E7, which disrupt p53 or $\mathrm{Rb}$ pathway respectively, has rather favored a $\mathrm{Rb}$-dependent mechanism. Indeed, E7 expression completely overcomes PML IV induced senescence while E6 expression has a lesser effect $(59,60)$. $\mathrm{pRB}$ and E2F are sequestered in NBs after enforced PML IV expression thus inhibiting E2F dependent proliferation and DNA repair, leading to p53 activation and senescence (34). This raises the issue of the respective roles of p53 and $\mathrm{Rb}$ in enforcing PML-driven senescence (Figure 1).

Altogether, these data demonstrate a front seat role of PML in cellular growth control. PML has clear suppressive function, but whether senescence loss in cancer is due to general PML decrease or only to PML IV specific loss remains an open question. Intriguingly, senescence induction by PML IV was suggested to be a NB-independent function. Indeed, the Cytomegalovirus oncoprotein IE1 disrupts NBs, but does not prevent PML IV 


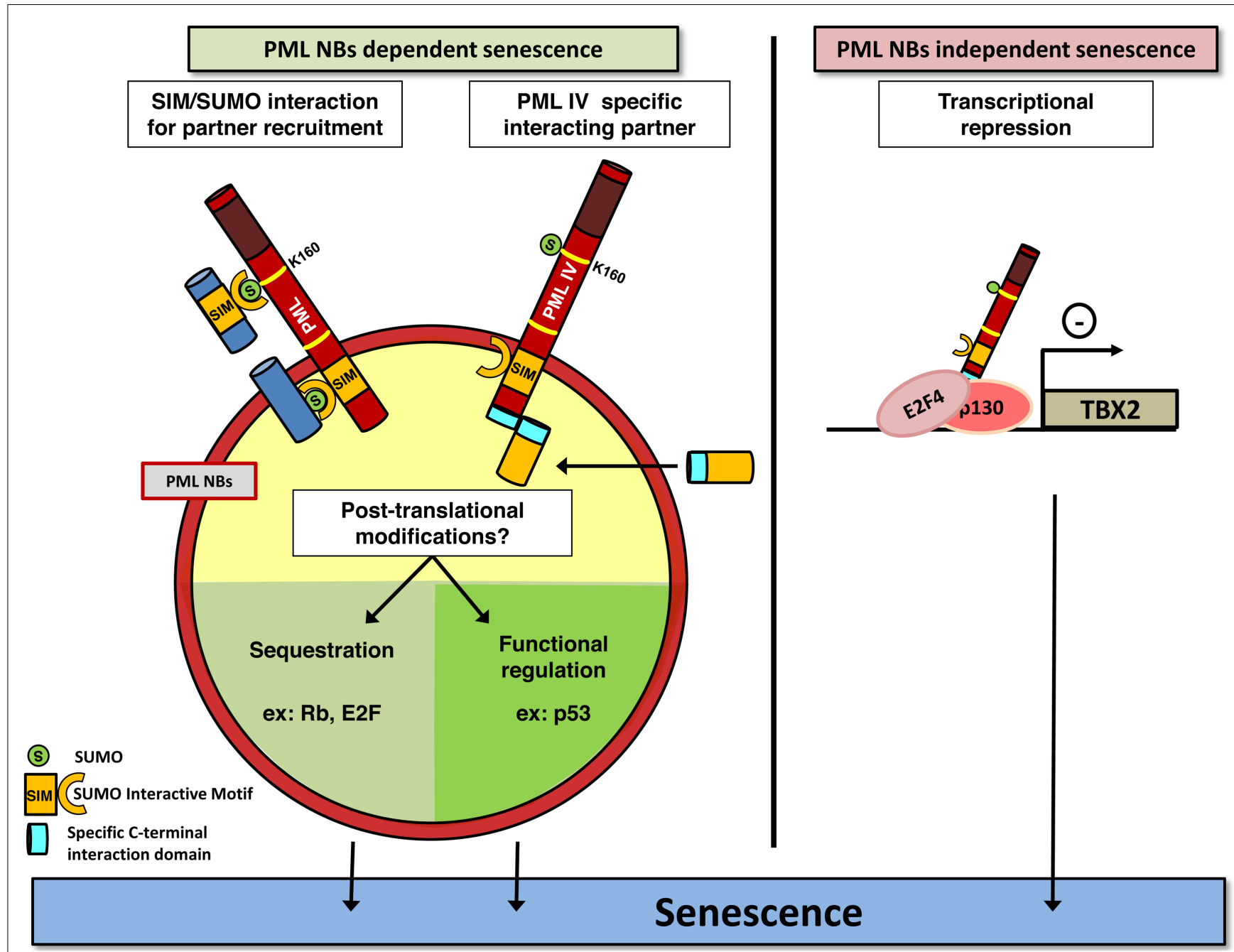

FIGURE 1 | PML induces senescence. PML may play a crucial role in senescence induction in a NBs-dependent (left) or independent (right) manner. PML (red) recruits partners (dark blue) through SUMOylation of the key K160 residue. SUMO and SIM motifs are indicated. PML IV could also recruit specific partners into NBs, through a specific binding domain (light blue). This may ultimately favor post-translational modifications of proteins controlling senescence, which converge on E2F and p53. Alternatively, PML IV can act independently of NBs structures, for example, as a transcriptional modulator of specific target genes. As disruption of NBs is a consequence of PML-RARA expression, this model could explain the lack of senescence in APL cells by both the loss of these modification platforms, and loss of PML C-terminal tails and hence defects in specific partners recruitment. from triggering senescence (37). In that respect, a last mechanism, which does not require PML NBs formation for PML IV function, was recently described. TBX2 is a transcription factor known to bypass senescence through induction of ARF (CDKN2A locus product $\mathrm{p} 14^{\mathrm{ARF}}$ ) and $\mathrm{p} 21$ repression and to be amplified in several types of cancer $(61,62)$. TBX2 interacts with PML protein but is not present in NBs $(63,64)$. However, only PML IV down regulates TBX2 transcription by direct association to its promoter, which leads to senescence. Conversely, TBX2 overexpression inhibits PML IV induced senescence (64). PML IV can also bind to nEGFR, a nuclear form of EGF receptor that exhibits transcriptional activity toward proliferation genes like Cyclin D1 gene, and represses their transcriptional activity. EGF receptor is frequently overexpressed or constitutively activated in non-small cell lung cancer and PML IV isoform expression specifically can repress the growth of these cells (65). Collectively, studies implicating PML IV overexpression have demonstrated a critical role of p53 activation, but the actual molecular mechanism(s) implicated somehow remain(s) under study.

\section{SUMOYLATION AND SENESCENCE}

SUMO overexpression also triggers senescence. Indeed, in HEK and MEF 3T3 cells, overexpression of SUMO-2/3 induces premature senescence (66). In contrast, non-conjugable mutants of SUMO-2/3 failed to induce senescence, suggesting that the increase of SUMO-2/3 conjugation on target proteins is responsible for senescence and not the increase of free SUMO-2/3 in the cell (66). In old rats and senescent fibroblasts in culture, SUMO expression increases with aging and hyper-SUMOylated protein forms become more abundant (67-69). Overexpression 
of SUMO-1 or SUMO-2 in Caenorhabditis elegans led to shortened life span and reproduction disorder (70), while loss of SUMOylation process resulted in severe zebrafish development defects (71) or misdifferentiation and microtumors development of hematopoietic progenitors in Drosophila (72). Altogether, these experiments confirm the crucial role of SUMO in development and tumor suppression. SUMO-induced senescence also implicates p53 and pRB, the two major tumor suppressive pathways. Indeed, down-regulation of $\mathrm{p} 53$ or $\mathrm{pRB}$ by RNA interference counteracts the senescent phenotype induced by SUMO-2/3 overexpression (66). These two proteins are themselves subjected to SUMOylation by both SUMO-1 and SUMO-2/3 paralogs (73-75). Little is known about the functional consequences of SUMO-modified pRB, apart from the fact that pRB SUMOylation mutant seems to be more efficient in E2F repression (75). Two other partners of the $\mathrm{pRB}$ pathway have been reported to be SUMOylated. Retinoblastoma binding protein 1 (RBP1) and Stra13 proteins are two transcriptional repressors implicated in cell cycle regulation. In both cases, SUMOylation enhances their repressor activity, leading to cellular arrest and senescence (76, 77). For p53 regulation, SUMOylation clearly acts as a transcriptional modulator, but whether this modification is activating or inhibiting is still under debate, and probably depends on the target genes and the cellular context $(78,79)$. However a recent in vitro study analyzed DNA binding and transcription properties of purified SUMO-1-p53 (80). SUMOylation inhibits binding and transcription of the $\mathrm{p} 21$ promoter, and prevents p53 acetylation, arguing that SUMOylation would have an inhibitory effect on $\mathrm{p} 53$. In a second study, a gene expression profile was performed by micro-array after expression of wild-type p53 or of a SUMO-1-p53 fusion (81). SUMO-1 modification of p53 can stimulate the expression of a few target genes, but its principal effect seemed to alleviate the trans-repression activity of p53.

\section{SUMOYLATION ENZYMES MODULATE SENESCENCE}

Complete loss of SUMOylation is embryonic lethal as shown by E1 activating enzyme knockout in Drosophila and E2 ligase Ubc9 knockout in mice or its homolog SAE2 in plants (82-84). Partial loss of SUMO machinery enzymes activity or expression level, including SENP proteases and E3 ligases, also triggers many cellular defects. Some situations linking SENP1 and SENP2 repression to senescent phenotype have been observed. Acute repression of SENP1 by shRNA retroviral infection induces Human Foreskin Fibroblast (HFF) cells premature senescence correlated with a strong accumulation of high molecular weight SUMO-1 conjugates (85) located in PML NBs. This phenotype has also been described with SENP2 and SENP7 repression and SUMO-2/3 consecutive accumulation. In another study, the silencing of the nuclear pore protein $\mathrm{Tpr}$ is responsible for senescence of HeLa and U2OS cells through reduction of SENP2 level (86). Interestingly, the Tpr-induced senescence is reversed by SUMO-1 siRNA extinction, emphasizing the importance of SUMO pathway in senescence. It worth mentioning that SENP depletion induced senescence is dependent on p53 activity, and it would be interesting to evaluate the role of SUMOylated p53 in this context. Overexpression of the SUMO E3 ligase PIASy has been associated with senescence induction in human fibroblasts (87). Direct interaction of PIASy with pRB and $\mathrm{p} 53$ promotes $\mathrm{pRB}$ transcriptional repression of E2F target genes and p53 SUMOylation and transcriptional activation (87). The ubiquitin ligase TRIM32, mutated in limb-girdle muscular dystrophy $2 \mathrm{H}$ disease (LGMD2H), normally targets PIASy for degradation. TRIM32 deficient mice harbor PIASy and SUMOylated proteins accumulation leading to premature senescence of muscle satellite cells (88). Nevertheless, PIASy induced senescence may strongly depend on cellular context since two other studies point out its proliferative effect and cell cycle re-entry capacity $(89,90)$.

ARF, a key regulator of p53 pathway, was also shown to play a role in SUMOylation. If ARF tumor-suppressor activity is mainly mediated through p53, ARF also exerts p53-independent functions since its overexpression in $\mathrm{p} 53$-null MEFs triggers proliferation arrest (91). One of these p53-independent roles could link ARF to SUMO modifications, as ARF overexpression induces an increase of global SUMOylation in 293T, U2OS, and 8054 human colon cancer cells expressing His tagged SUMO-1. ARF also promotes the SUMOylation of various specific targets, among them $\mathrm{Hdm} 2$, p53, p63, NPM, E2F1, Werners Helicase (WRN), and others (9296). To note, ARF-induced SUMOylation of $\mathrm{Hdm} 2$ seems not to interfere with p53 signaling, and would be part of another cellular process (95). Finally, ARF was shown to specifically interact with the E2 SUMO ligase Ubc9 making the link with the target proteins, thus arguing that ARF may be an effective E3 SUMO ligase (94).

\section{A CONNECTION BETWEEN PML AND SUMOS FOR SENESCENCE CONTROL?}

Taken the key roles of SUMO and PML in promoting senescence and the profound effects of SUMOs on PML biology and NBorganization, it is tempting to propose that the two pathways could be connected. Many reciprocal interactions exist between SUMO and PML. Global increase of SUMOylated proteins provoked by SENP1 repression induces NBs enlargement (85). PML IV was suggested to behave as an E3 SUMO ligase for p53 and HDM2 (97). The other PML isoforms, ineffective at inducing senescence, do not enhance p53 SUMOylation, suggesting that this modification may contribute to the senescent phenotype. PML overexpression could increase recruitment of SUMO machinery and consequently enhance global SUMOylation, provoking premature senescence. Indeed, NBs concentrate a large amount of SUMOylated proteins compared to other cellular compartments (19). Then, the tumorigenic switch observed in cancer after loss of PML NBs might either be explained by primary alterations of SUMOylation homeostasis leading to secondary defects in NB-assembly or, alternatively, to altered global SUMOylation as a consequence of PML loss (Figure 2).

Finally, SUMO modification participates in cellular senescence through modulation of oxidative stress responses (Figure 2). In this context, it has been shown that SUMOylation of HIPK2 (98) or key enzyme such as NADPH oxidase 2 (99) can inhibit their functions and consequently may control redox status (Figure 2). Interestingly, the fact that PML is sensitive to oxidative stress, through the formation of disulfide bridges that trigger NBbiogenesis (100), could contribute to stress-induced SUMOylation 


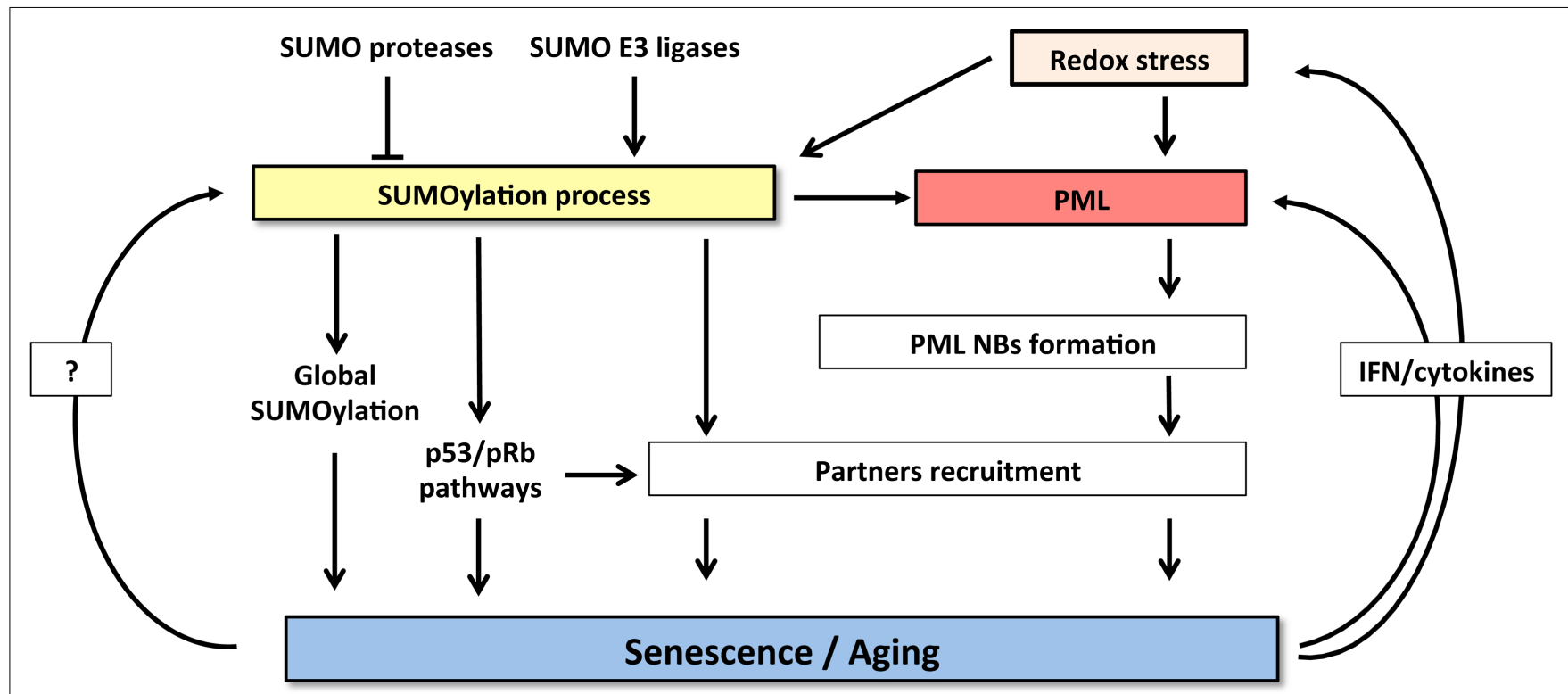

FIGURE 2 | Crosstalk between SUMOylation machinery and PML pathway controls senescence induction. SUMOylation process and PML NBs functions are highly cross-connected. Increase of both SUMO and PML levels induces senescence. SUMOylation enzymes regulate NBs formation and partners' recruitment. Conversely, NBs could potentiate SUMOylation process and partners modification. Finally, senescent cells express specific cytokines (IFNs or IL-6) that, in a positive feedback loop, enhance PML expression and also induce oxidative stress further enforcing NBs formation. and cooperate to mediate senescence. Taken the rising importance of senescence, SUMOs, and PML in cancer genesis and also therapy response, exciting future developments are to be expected in this rapidly moving field.

\section{ACKNOWLEDGMENTS}

We apologize to our friends and colleagues whose primary work could not be cited because of space restrictions. The laboratory is

\section{REFERENCES}

1. Hayflick L, Moorhead PS. The serial cultivation of human diploid cell strains. Exp Cell Res (1961) 25:585-621. doi:10.1016/00144827(61)90192-6

2. Dimri GP, Lee X, Basile G, Acosta M, Scott G, Roskelley C, et al. A biomarker that identifies senescent human cells in culture and in aging skin in vivo. Proc Natl Acad Sci U S A (1995) 92:9363-7. doi:10.1073/pnas.92.20.9363

3. Krishnamurthy J, Torrice C, Ramsey MR, Kovalev GI, Al-Regaiey $\mathrm{K}, \mathrm{Su} \mathrm{L}$, et al. Ink4a/Arf expression is a biomarker of aging. $J$ Clin Invest (2004) 114:1299-307. doi:10.1172/JCI200422475

4. Harley CB, Futcher AB, Greider CW. Telomeres shorten during ageing of human fibroblasts. Nature (1990)
345:458-60. doi:10.1038/3454 $58 \mathrm{a} 0$

5. D'Adda Di Fagagna F, Reaper PM, Clay-Farrace L, Fiegler H, Carr P, Von Zglinicki $\mathrm{T}$, et al. A DNA damage checkpoint response in telomere-initiated senescence. Nature (2003) 426:194-8. doi:10.1038/nature02118

6. Takai H, Smogorzewska A, De Lange T. DNA damage foci at dysfunctional telomeres. Curr Biol (2003) 13:1549-56. doi:10.1016/S09609822(03)00542-6

7. Shay JW, Pereira-Smith OM, Wright WE. A role for both $\mathrm{RB}$ and $\mathrm{p} 53$ in the regulation of human cellular senescence. Exp Cell Res (1991) 196:33-9. doi:10.1016/00144827(91)90453-2

8. Dimri GP. What has senescence got to do with cancer?

supported by INSERM, CNRS, Université Paris Diderot, Institut Universitaire de France, Ligue Contre le Cancer, Institut National $\mathrm{du}$ Cancer, Saint Louis Institute and PACRI (ANR), Association pour la Recherche contre le Cancer (Griffuel Award to Hugues De Thé), Canceropôle Ile de France, and the European Research Council (STEMAPL advanced grant to Hugues De Thé). Lisa Ivanschitz is supported by Grant from Ligue Nationale contre le Cancer. We thank all members of the laboratory for discussions.

Cancer Cell (2005) 7:505-12. doi:10.1016/j.ccr.2005.05.025

9. Caino MC, Meshki J, Kazanietz MG. Hallmarks for senescence in carcinogenesis: novel signaling players. Apoptosis (2009) 14:392-408. doi:10.1007/s10495-009-0316-z

10. Bohren KM, Nadkarni V, Song JH, Gabbay KH, Owerbach D. A $\mathrm{M} 55 \mathrm{~V}$ polymorphism in a novel SUMO gene (SUMO-4) differentially activates heat shock transcription factors and is associated with susceptibility to type I diabetes mellitus. J Biol Chem (2004) 279:272338. doi:10.1074/jbc.M40227 3200

11. Wilkinson KA, Henley JM. Mechanisms, regulation and consequences of protein SUMOylation. Biochem J (2010) 428:133-45. doi:10.1042/BJ20100158
12. Melchior F. SUMO - nonclassical ubiquitin. Annu Rev Cell Dev Biol (2000) 16:591-626. doi:10.1146/annurev.cellbio.16. 1.591

13. Sampson DA, Wang M, Matunis MJ. The small ubiquitin-like modifier-1 (SUMO-1) consensus sequence mediates Ubc9 binding and is essential for SUMO-1 modification. J Biol Chem (2001) 276:216649. doi:10.1074/jbc.M10000 6200

14. Kahyo T, Nishida T, Yasuda $\mathrm{H}$. Involvement of PIAS1 in the sumoylation of tumor suppressor p53. Mol Cell (2001) 8:713-8. doi:10.1016/S10972765(01)00349-5

15. Kim JH, Baek SH. Emerging roles of desumoylating enzymes. Biochim Biophys Acta (2009) 1792:155-62. doi:10.1016/j.bbadis.2008.12.008 
16. Nagai S, Davoodi N, Gasser SM. Nuclear organization in genome stability: SUMO connections. Cell Res (2011) 21:47485. doi:10.1038/cr.2011.31

17. Daniel MT, Koken M, Romagne O, Barbey S, Bazarbachi A, Stadler M, et al. PML protein expression in hematopoietic and acute promyelocytic leukemia cells. Blood (1993) 82:1858-67.

18. Koken MH, Puvion-Dutilleul F, Guillemin MC, Viron A, LinaresCruz G, Stuurman $\mathrm{N}$, et al. The $t(15 ; 17)$ translocation alters a nuclear body in a retinoic acid-reversible fashion. $E M B O J$ (1994) 13:1073-83.

19. Van Damme E, Laukens K, Dang TH, Van Ostade X. A manually curated network of the PML nuclear body interactome reveals an important role for PMLNBs in SUMOylation dynamics. Int J Biol Sci (2010) 6:51-67. doi:10.7150/ijbs.6.51

20. Boddy MN, Howe K, Etkin LD, Solomon E, Freemont PS. PIC 1 , a novel ubiquitin-like protein which interacts with the PML component of a multiprotein complex that is disrupted in acute promyelocytic leukaemia. Oncogene (1996) 13:971-82.

21. Muller S, Matunis MJ, Dejean A. Conjugation with the ubiquitinrelated modifier SUMO-1 regulates the partitioning of PML within the nucleus. EMBO J (1998) 17:61-70. doi:10.1093/emboj/17.1.61

22. Shen TH, Lin HK, Scaglioni PP, Yung TM, Pandolfi PP. The mechanisms of PMLnuclear body formation. Mol Cell (2006) 24:331-9. doi:10.1016/j.molcel.2006.09.013

23. Duprez E, Saurin AJ, Desterro JM, Lallemand-Breitenbach V, Howe $\mathrm{K}$, Boddy $\mathrm{MN}$, et al. SUMO-1 modification of the acute promyelocytic leukaemia protein PML: implications for nuclear localisation. J Cell Sci (1999) 112(Pt 3):381-93.

24. Lallemand-Breitenbach V, Zhu J, Puvion F, Koken M, Honore $\mathrm{N}$, Doubeikovsky A, et al. Role of promyelocytic leukemia (PML) sumolation in nuclear body formation, $11 \mathrm{~S}$ proteasome recruitment, and As2O3induced PML or PML/retinoic acid receptor alpha degradation. J Exp Med (2001) 193:1361-71. doi:10.1084/jem.193.12.1361

25. Lin DY, Huang YS, Jeng JC, Kuo HY, Chang CC, Chao
TT, et al. Role of SUMOinteracting motif in Daxx SUMO modification, subnuclear localization, and repression of sumoylated transcription factors. Mol Cell (2006) 24:34154. doi:10.1016/j.molcel.2006. 10.019

26. Cho G, Lim Y, Golden JA. SUMO interaction motifs in Sizn1 are required for promyelocytic leukemia protein nuclear body localization and for transcriptional activation. $J$ Biol Chem (2009) 284:19592-600. doi:10.1074/jbc.M109.010181

27. Lallemand-Breitenbach V, Jeanne M, Benhenda S, Nasr R, Lei M, Peres L, et al. Arsenic degrades PML or PML-RARalpha through a SUMO-triggered RNF4/ubiquitin-mediated pathway. Nat Cell Biol (2008) 10:547-55. doi:10.1038/ncb1717

28. De The H, Lavau C, Marchio A, Chomienne C, Degos L, Dejean A. The PML-RAR alpha fusion mRNA generated by the $\mathrm{t}(15 ; 17)$ translocation in acute promyelocytic leukemia encodes a functionally altered RAR. Cell (1991) 66:675-84. doi:10.1016/00928674(91)90113-D

29. Zhu J, Lallemand-Breitenbach $V$, De The H. Pathways of retinoic acid- or arsenic trioxideinduced PML/RARalpha catabolism, role of oncogene degradation in disease remission. Oncogene (2001) 20:7257-65. doi:10.1038/sj.onc. 1204852

30. De The $\mathrm{H}$, Chen Z. Acute promyelocytic leukaemia: novel insights into the mechanisms of cure. Nat Rev Cancer (2010) 10:775-83. doi:10.1038/nrc2943

31. Koken MH, Linares-Cruz G, Quignon F, Viron A, Chelbi-Alix MK, Sobczak-Thepot J, et al. The PML growth-suppressor has an altered expression in human oncogenesis. Oncogene (1995) 10:1315-24.

32. Gurrieri C, Capodieci P, Bernardi R, Scaglioni PP, Nafa K, Rush LJ, et al. Loss of the tumor suppressor PML in human cancers of multiple histologic origins. J Natl Cancer Inst (2004) 96:269-79. doi:10.1093/jnci/djh043

33. Scaglioni PP, Yung TM, Cai LF, Erdjument-Bromage $\mathrm{H}$, Kaufman AJ, Singh B, et al. A CK2dependent mechanism for degradation of the PML tumor suppressor. Cell (2006) 126:269-83. doi:10.1016/j.cell.2006.05.041
34. Vernier $M$, Bourdeau V, Gaumont-Leclerc MF, Moiseeva O, Begin V, Saad F, et al. Regulation of E2Fs and senescence by PML nuclear bodies. Genes Dev (2011) 25:41-50. doi:10.1101/gad.1975111

35. Ferbeyre G, De Stanchina E, Querido E, Baptiste N, Prives C, Lowe SW. PML is induced by oncogenic ras and promotes premature senescence. Genes Dev (2000) 14:2015-27.

36. Pearson M, Carbone R, Sebastiani C, Cioce M, Fagioli M, Saito $S$, et al. PML regulates p53 acetylation and premature senescence induced by oncogenic Ras. Nature (2000) 406:207-10. doi:10.1038/35018127

37. Bischof O, Kirsh O, Pearson M, Itahana K, Pelicci PG, Dejean A. Deconstructing PMLinduced premature senescence. ЕMBO J (2002) 21:3358-69. doi:10.1093/emboj/cdf341

38. Stadler M, Chelbi-Alix MK, Koken MH, Venturini L, Lee C, Saib A, et al. Transcriptional induction of the PML growth suppressor gene by interferons is mediated through an ISRE and a GAS element. Oncogene (1995) 11:2565-73.

39. De Stanchina E, Querido E, Narita M, Davuluri RV, Pandolfi PP, Ferbeyre G, et al. PML is a direct p53 target that modulates p53 effector functions. Mol Cell (2004) 13:523-35. doi:10.1016/S10972765(04)00062-0

40. Moiseeva O, Mallette FA, Mukhopadhyay UK, Moores A, Ferbeyre G. DNA damage signaling and $\mathrm{p} 53$-dependent senescence after prolonged beta-interferon stimulation. $\mathrm{Mol}$ Biol Cell (2006) 17:1583-92. doi:10.1091/mbc.E05-09-0858

41. Chiantore MV, Vannucchi S, Accardi R, Tommasino M, Percario ZA, Vaccari G, et al. Interferon-beta induces cellular senescence in cutaneous human papilloma virus-transformed human keratinocytes by affecting p53 transactivating activity. PLoS ONE (2012) 7:e36909. doi:10.1371/journal.pone.003 6909

42. Hubackova S, Novakova Z, Krejcikova K, Kosar M, Dobrovolna J, Duskova P, et al. Regulation of the PML tumor suppressor in druginduced senescence of human normal and cancer cells by
JAK/STAT-mediated signaling. Cell Cycle (2010) 9:3085-99. doi:10.4161/cc.9.15.12521

43. Novakova Z, Hubackova S, Kosar M, Janderova-Rossmeislova L, Dobrovolna J, Vasicova P, et al. Cytokine expression and signaling in druginduced cellular senescence. Oncogene (2010) 29:273-84. doi:10.1038/onc.2009.318

44. Campisi J, Andersen JK, Kapahi P, Melov S. Cellular senescence: a link between cancer and age-related degenerative disease? Semin Cancer Biol (2011) 21:354-9. doi:10.1016/j.semcancer.2011. 09.001

45. Reineke EL, Lam M, Liu Q, Liu $\mathrm{Y}$, Stanya KJ, Chang KS, et al. Degradation of the tumor suppressor PML by Pin 1 contributes to the cancer phenotype of breast cancer MDA-MB-231 cells. Mol Cell Biol (2008) 28:997-1006. doi:10.1128/MCB.01848-07

46. Fukuyo $\mathrm{Y}$, Takahashi A, Hara E, Horikoshi N, Pandita TK, Nakajima T. E2FBP1 antagonizes the p16(INK4A)-Rb tumor suppressor machinery for growth suppression and cellular senescence by regulating promyelocytic leukemia protein stability. Int J Oral Sci (2011) 3:200-8. doi:10.4248/IJOS11071

47. Wolyniec K, Shortt J, De Stanchina E, Levav-Cohen Y, Alsheich-Bartok O, LouriaHayon I, et al. E6AP ubiquitin ligase regulates $\mathrm{PML}$-induced senescence in Myc-driven lymphomagenesis. Blood (2012) 120:822-32. doi:10.1182/blood2011-10-387647

48. Rabellino A, Carter B, Konstantinidou G, Wu SY, Rimessi A, Byers LA, et al. The SUMO E3ligase PIAS1 regulates the tumor suppressor PML and its oncogenic counterpart PML-RARA. Cancer Res (2012) 72:2275-84. doi:10.1158/0008-5472.CAN11-3159

49. Scaglioni PP, Rabellino A, Yung TM, Bernardi R, Choi S, Konstantinidou G, et al. Translation-dependent mechanisms lead to PML upregulation and mediate oncogenic K-RAS-induced cellular senescence. $\quad E M B O$ Mol Med (2012) 4:594-602. doi:10.1002/emmm.201200233

50. Guo A, Salomoni P, Luo J, Shih A, Zhong S, Gu W, et al. The function of PML in p53-dependent 
apoptosis. Nat Cell Biol (2000) 2:730-6. doi:10.1038/35036365

51. Takahashi K, Yoshida N, Murakami N, Kawata K, Ishizaki $\mathrm{H}$, Tanaka-Okamoto $\mathrm{M}$, et al. Dynamic regulation of p53 subnuclear localization and senescence by MORC3. Mol Biol Cell (2007) 18:1701-9. doi:10.1091/mbc.E06-08-0747

52. Pan D, Zhu Q, Luo K. SnoN functions as a tumour suppressor by inducing premature senescence. EMBO J (2009) 28:350013. doi:10.1038/emboj.2009.250

53. Rokudai S, Laptenko O, Arnal SM, Taya Y, Kitabayashi I, Prives C. MOZ increases p53 acetylation and premature senescence through its complex formation with PML. Proc Natl Acad Sci U S A (2013) 110:3895-900. doi:10.1073/pnas.1300490110

54. Hofmann TG, Moller A, Sirma H, Zentgraf H, Taya Y, Droge W, et al. Regulation of p53 activity by its interaction with homeodomaininteracting protein kinase-2. Nat Cell Biol (2002) 4:1-10. doi:10.1038/ncb715

55. Moller A, Sirma H, Hofmann TG, Rueffer S, Klimczak E, Droge $\mathrm{W}$, et al. PML is required for homeodomain-interacting protein kinase 2 (HIPK2)-mediated p53 phosphorylation and cell cycle arrest but is dispensable for the formation of HIPK domains. Cancer Res (2003) 63:4310-4.

56. Sung KS, Lee YA, Kim ET, Lee SR, Ahn JH, Choi CY. Role of the SUMO-interacting motif in HIPK2 targeting to the PML nuclear bodies and regulation of p53. Exp Cell Res (2011) 317:1060-70. doi:10.1016/j.yexcr.2010.12.016

57. Langley E, Pearson M, Faretta M, Bauer UM, Frye RA, Minucci S, et al. Human SIR2 deacetylates p53 and antagonizes PML/p53induced cellular senescence. EMBO J (2002) 21:2383-96. doi:10.1093/emboj/21.10.2383

58. Peche LY, Scolz M, Ladelfa MF, Monte M, Schneider C. MageA2 restrains cellular senescence by targeting the function of PMLIV/p53 axis at the PML-NBs. Cell Death Differ (2012) 19:926-36. doi:10.1038/cdd.2011.173

59. Mallette FA, Goumard S, Gaumont-Leclerc MF, Moiseeva O, Ferbeyre G. Human fibroblasts require the $\mathrm{Rb}$ family of tumor suppressors, but not p53, for PML-induced senescence. Oncogene (2004) 23:91-9. doi:10.1038/sj.onc.1206886

60. Bischof O, Nacerddine K, Dejean A. Human papillomavirus oncoprotein E7 targets the promyelocytic leukemia protein and circumvents cellular senescence via the $R b$ and $p 53$ tumor suppressor pathways. Mol Cell Biol (2005) 25:1013-24. doi:10.1128/MCB.25.3.10131024.2005

61. Jacobs JJ, Keblusek P, RobanusMaandag E, Kristel P, Lingbeek M, Nederlof PM, et al. Senescence bypass screen identifies TBX2, which represses Cdkn2a (p19(ARF)) and is amplified in a subset of human breast cancers. Nat Genet (2000) 26:291-9. doi:10.1038/81583

62. Prince S, Carreira S, Vance KW, Abrahams A, Goding CR. Tbx2 directly represses the expression of the p21(WAF1) cyclindependent kinase inhibitor. Cancer Res (2004) 64:1669-74. doi:10.1158/0008-5472.CAN03-3286

63. Bilican B, Goding CR. Cell cycle regulation of the T-box transcription factor tbx2. Exp Cell Res (2006) 312:2358-66. doi:10.1016/j.yexcr.2006.03.033

64. Martin N, Benhamed M, Nacerddine $\mathrm{K}$, Demarque MD, Van Lohuizen M, Dejean A, et al. Physical and functional interaction between PML and TBX2 in the establishment of cellular senescence. EMBO J (2012) 31:95-109. doi:10.1038/emboj.2011.370

65. Kuo HY, Chen YC, Chang HY, Jeng JC, Lin EH, Pan CM, et al. The PML isoform IV is a negative regulator of nuclear EGFR's transcriptional activity in lung cancer. Carcinogenesis (2013). doi:10.1093/carcin/bgt109. [Epub ahead of print].

66. Li T, Santockyte R, Shen RF, Tekle E, Wang G, Yang DC, et al. Expression of SUMO-2/3 induced senescence through $\mathrm{p} 53$ and pRB-mediated pathways. $J$ Biol Chem (2006) 281:36221-7. doi:10.1074/jbc.M608236200

67. Bischof O, Dejean A. SUMO is growing senescent. Cell Cycle (2007) 6:677-81. doi:10.4161/cc.6.6.4021

68. Zhang L, Li F, Dimayuga E, Craddock J, Keller JN. Effects of aging and dietary restriction on ubiquitination, sumoylation, and the proteasome in the spleen.
FEBS Lett (2007) 581:5543-7. doi:10.1016/j.febslet.2007.10.054

69. Yang QG, Wang F, Zhang Q, Xu WR, Chen YP, Chen GH. Correlation of increased hippocampal Sumo3 with spatial learning ability in old C57BL/6 mice. Neurosci Lett (2012) 518:75-9. doi:10.1016/j.neulet.2012.04.051

70. Rytinki MM, Lakso M, Pehkonen P, Aarnio V, Reisner K, Perakyla $M$, et al. Overexpression of SUMO perturbs the growth and development of Caenorhabditis elegans. Cell Mol Life Sci (2011) 68:3219-32. doi:10.1007/s00018-011-0627-4

71. Yuan H, Zhou J, Deng M, Liu $\mathrm{X}$, Le Bras M, De The H, et al. Small ubiquitin-related modifier paralogs are indispensable but functionally redundant during early development of zebrafish. Cell Res (2010) 20:185-96. doi:10.1038/cr.2009.101

72. Kalamarz ME, Paddibhatla I, Nadar C, Govind S. Sumoylation is tumor-suppressive and confers proliferative quiescence to hematopoietic progenitors in Drosophila melanogaster larvae. Biol Open (2012) 1:161-72. doi:10.1242/bio.2012043

73. Gostissa M, Hengstermann A, Fogal V, Sandy P, Schwarz SE, Scheffner $M$, et al. Activation of p53 by conjugation to the ubiquitin-like protein SUMO1. ЕMBO J (1999) 18:6462-71. doi:10.1093/emboj/18.22.6462

74. Rodriguez MS, Desterro JM, Lain S, Midgley CA, Lane DP, Hay RT. SUMO-1 modification activates the transcriptional response of p53. EMBO J (1999) 18:6455-61. doi:10.1093/emboj/18.22.6455

75. Ledl A, Schmidt D, Muller S. Viral oncoproteins E1A and E7 and cellular LxCxE proteins repress SUMO modification of the retinoblastoma tumor suppressor. Oncogene (2005) 24:3810-8. doi:10.1038/si.onc.1208539

76. Binda O, Roy JS, Branton PE. RBP1 family proteins exhibit SUMOylation-dependent transcriptional repression and induce cell growth inhibition reminiscent of senescence. Mol Cell Biol (2006) 26:1917-31. doi:10.1128/MCB.26.5.19171931.2006

77. Wang Y, Rao VK, Kok WK, Roy DN, Sethi S, Ling BM, et al. SUMO modification of Stral3 is required for repression of cyclin D1 expression and cellular growth arrest.
PLoS ONE (2012) 7:e43137. doi:10.1371/journal.pone.004 3137

78. Melchior F, Hengst L. SUMO-1 and p53. Cell Cycle (2002) 1:2459. doi:10.4161/cc.1.4.131

79. Hock A, Vousden KH. Regulation of the p53 pathway by ubiquitin and related proteins. Int $J$ Biochem Cell Biol (2010) 42:1618-21. doi:10.1016/j.biocel.2010.06.011

80. Wu SY, Chiang CM. Crosstalk between sumoylation and acetylation regulates p53dependent chromatin transcription and DNA binding. EMBO J (2009) 28:1246-59. doi:10.1038/emboj.2009.83

81. Cheema A, Knights CD, Rao M, Catania J, Perez R, Simons $\mathrm{B}$, et al. Functional mimicry of the acetylated C-terminal tail of p53 by a SUMO1 acetylated domain, SAD. $J$ Cell Physiol (2010) 225:371-84. doi:10.1002/jcp.22224

82. Nacerddine $K$, Lehembre $F$, Bhaumik M, Artus J, CohenTannoudji $\mathrm{M}$, Babinet $\mathrm{C}$, et al. The SUMO pathway is essential for nuclear integrity and chromosome segregation in mice. Dev Cell (2005) 9:769-79. doi:10.1016/j.devcel.2005.10.007

83. Saracco SA, Miller MJ, Kurepa J, Vierstra RD. Genetic analysis of SUMOylation in Arabidopsis: conjugation of SUMO1 and SUMO2 to nuclear proteins is essential. Plant Physiol (2007) 145:119-34. doi:10.1104/pp.107.102285

84. Kanakousaki K, Gibson MC. A differential requirement for SUMOylation in proliferating and non-proliferating cells during Drosophila development. Development (2012) 139:275162. doi:10.1242/dev.082974

85. Yates KE, Korbel GA, Shtutman M, Roninson IB, Dimaio D. Repression of the SUMOspecific protease Senp1 induces p53-dependent premature senescence in normal human fibroblasts. Aging Cell (2008) 7:609-21. doi:10.1111/j.14749726.2008.00411.x

86. David-Watine B. Silencing nuclear pore protein Tpr elicits a senescent-like phenotype in cancer cells. PLoS ONE (2011) 6:e22423. doi:10.1371/journal.pone.002 2423

87. Bischof O, Schwamborn K, Martin N, Werner A, Sustmann C, 
Grosschedl R, et al. The E3 SUMO ligase PIASy is a regulator of cellular senescence and apoptosis. Mol Cell (2006) 22:78394. doi:10.1016/j.molcel.2006.0 5.016

88. Kudryashova E, Kramerova I, Spencer MJ. Satellite cell senescence underlies myopathy in a mouse model of limb-girdle muscular dystrophy $2 \mathrm{H}$. J Clin Invest (2012) 122:1764-76. doi:10.1172/JCI5958

89. Zhou S, Si J, Liu T, Dewille JW. PIASy represses CCAAT/enhancer-binding protein delta (C/EBPdelta) transcriptional activity by sequestering $\mathrm{C} / \mathrm{EBPdel}$ ta the nuclear periphery. $J$ Biol Chem (2008) 283:20137-48. doi:10.1074/jbc.M801307200

90. Zhang C, Yuan X, Yue L, Fu J, Luo L, Yin Z. PIASy interacts with p73alpha and regulates cell cycle in HEK293 cells. Cell Immunol (2010) 263:23540. doi:10.1016/j.cellimm.2010. 04.005

91. Carnero A, Hudson JD, Price CM, Beach DH. pl6INK4A and
p19ARF act in overlapping pathways in cellular immortalization. Nat Cell Biol (2000) 2:148-55. doi:10.1038/35004020

92. Xirodimas DP, Chisholm J, Desterro JM, Lane DP, Hay RT. P14ARF promotes accumulation of SUMO-1 conjugated (H)Mdm2. FEBS Lett (2002) 528:207-11. doi:10.1016/S00145793(02)03310-0

93. Chen L, Chen J. MDM2-ARF complex regulates p53 sumoylation. Oncogene (2003) 22:534857. doi:10.1038/sj.onc. 1206851

94. Rizos H, Woodruff S, Kefford RF. p14ARF interacts with the SUMO-conjugating enzyme Ubc 9 and promotes the sumoylation of its binding partners. Cell Cycle (2005) 4:597-603. doi:10.4161/cc.4.4.1588

95. Tago K, Chiocca S, Sherr CJ. Sumoylation induced by the Arf tumor suppressor: a p53-independent function. Proc Natl Acad Sci U S A (2005) 102:7689-94. doi:10.1073/pnas.0502978102

96. Vivo M, Di Costanzo A, Fortugno P, Pollice A, Calabro
V, La Mantia G. Downregulation of DeltaNp63alpha in keratinocytes by p14ARF-mediated SUMO-conjugation and degradation. Cell Cycle (2009) 8:353743. doi:10.4161/cc.8.21.9954

97. Chu Y, Yang X. SUMO E3 ligase activity of TRIM proteins. Oncogene (2011) 30:110816. doi:10.1038/onc. 2010.462

98. De La Vega L, Grishina I, Moreno R, Kruger M, Braun T, Schmitz ML. A redox-regulated SUMO/acetylation switch of HIPK2 controls the survival threshold to oxidative stress. Mol Cell (2012) 46:472-83. doi:10.1016/j.molcel.2012. 03.003

99. Kim HJ, Yun J, Lee J, Hong H, Jeong J, Kim E, et al. SUMO1 attenuates stress-induced ROS generation by inhibiting NADPH oxidase 2. Biochem Biophys Res Commun (2011) 410:55562. doi:10.1016/j.bbrc.2011. 06.025

100. Jeanne $M, \quad$ LallemandBreitenbach V, Ferhi O, Koken M, Le Bras M, Duffort S, et al. PML/RARA oxidation and arsenic binding initiate the antileukemia response of As2 $\mathrm{O} 3$. Cancer Cell (2010) 18:88-98. doi:10.1016/j.ccr.2010.06.003

Conflict of Interest Statement: The authors declare that the research was conducted in the absence of any commercial or financial relationships that could be construed as a potential conflict of interest.

Received: 22 April 2013; accepted: 14 June 2013; published online: 04 July 2013.

Citation: Ivanschitz $L$, de Thé $H$ and Le Bras M (2013) PML, SUMOylation, and senescence. Front. Oncol. 3:171. doi: 10.3389/fonc.2013.00171

This article was submitted to Frontiers in Molecular and Cellular Oncology, a specialty of Frontiers in Oncology.

Copyright $\odot 2013$ Ivanschitz, de Thé and Le Bras. This is an open-access article distributed under the terms of the Creative Commons Attribution License, which permits use, distribution and reproduction in other forums, provided the original authors and source are credited and subject to any copyright notices concerning any third-party graphics etc. 